International Journal of Life Sciences
Available online at http://sciencescholar.us/journal/index.php/ijls
Vol. 3 No. 1, April 2019, pages: 1211
e-ISSN: 2550-6986, p-ISSN: $2550-6994$
https://doi.org/10.29332/ijls.v3n1.240

\title{
Susceptibility to Landslides in Los Angeles Campus: Southern State University of Manabi
}

\author{
(D) cosshark \\ Arturo Andres Hernandez Escobar a , Luis Gerardo Sandoval Santos ${ }^{\text {b }}$, Carlos Gustavo Villacreses \\ Viteri c, Maria Rodriguez Gamez d, Yamel de las Mercedes Alvarez Gutiérrez e
}

Article history: Received 27 July 2018, Accepted: 31 December 2018, Published: 8 January 2019

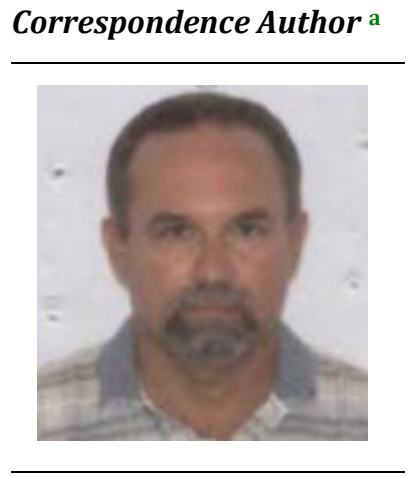

\section{Keywords}

geographic information

systems;

lithodemic units;

sliding;

susceptibility;

winter season;

\begin{abstract}
This research is of the correlational - explanatory type, based on the heuristic method, applying the Geographic Information Systems (GIS) as a tool, to obtain thematic maps and final susceptibility, considering its fundamental objective the evaluation of the areas susceptible to landslides. Through the spatial zoning of the "Los Angeles" campus of the "Southern State University of Manabí". The analysis of the variables of the conditioning factors, allowed to recognize three categories of susceptibility in the Los Angeles campus (High, Medium and Low), where lithological units converge as sandy clay, clay, and silts tone, steep slopes (over $50^{\circ}$ ), cuts of slopes devoid of some kind of protection, deforested and highly eroded soils. This implies that there is a likelihood of new affectations, which is why local risk management plans must be developed.
\end{abstract}

e-ISSN: 2550-6986, p-ISSN: 2550-6994@ Copyright 2019. The Author. SS Journals Published by Universidad Técnica de Manabí. This is an open-access article under the CC BY-SA 4.0 license (https://creativecommons.org/licenses/by-sa/4.0/) All rights reserved.

\section{Contents}

Abstract

1. Introduction

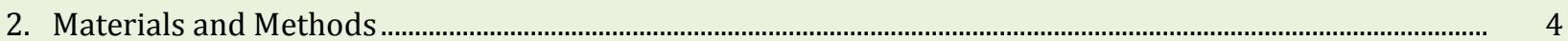

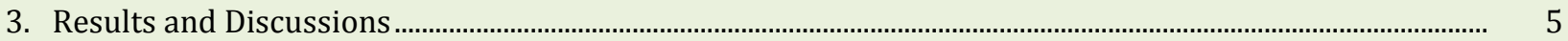

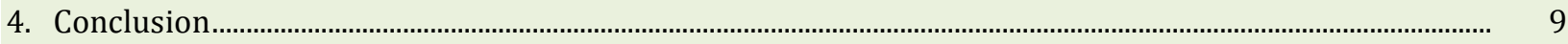

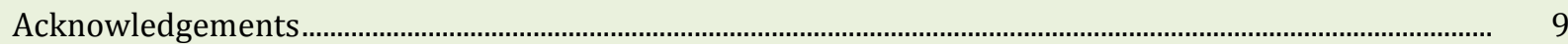

a Ph.D. in Pedagogical Sciences Universidad Estatal del sur de Manabi, (UNESUM), Jipijapa, Manabi, Ecuador

b Environmental Engineer, Universidad Estatal del sur de Manabi, (UNESUM), Jipijapa, Manabi, Ecuador

c MsC. Head, Dean and Associate Professor, Faculty of Sciences, Mathematics, Physics and Chemistry, Universidad Tecnica de Manabi, Portoviejo, Ecuador

d Ph.D. Strategies and Planning of the territory, Universidad Tecnica de Manabi, Portoviejo, Ecuador

e MsC. Environmental Administration, Universidad Estatal del Sur de Manabi, (UNESUM), Jipijapa, Manabi, Ecuador 


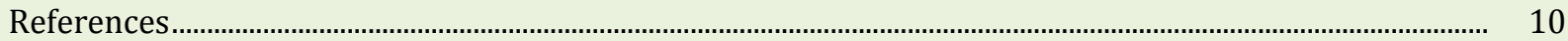

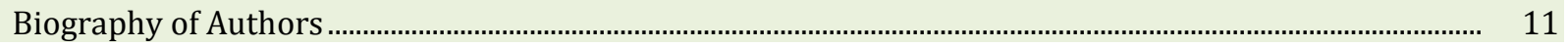

\section{Introduction}

Landslides have caused thousands of deaths and property damage worth tens of billions of dollars each year (Brabb \& Hrrod, 1989); however, very few people are aware of its importance. 90\% of landslide losses are avoidable if the problem is identified previously and preventive or control measures are taken (Suárez, 1998). In Latin America alone, the landslides have left very high numbers of victims and material losses, since countless human settlements are located at the foot of mountainous escarpments and on destabilized slopes. In 1993, the La Josefina landslide in Ecuador caused losses of 147 million dollars and 71 victims. These processes can be produced by different factors, conditions, and triggers (Meza et al., 2018).

In correspondence with the aim is intended, as an objective of the work, to evaluate the areas susceptible to landslides, through spatial zoning, the "Los Angeles" campus of the "Southern State University of Manabí". Coordinators of the Management Unit of Manabí risks, point out that in almost all the cantons there are landslides and some of them threaten to bury populated areas, being the cantons with the highest vulnerability: Sucre, Portoviejo, Montecristi, Jipijapa, Jaramijó, San Vicente, Santa Ana, Flavio Alfaro, El Carmen, and Chone. The only Manabi canton where these phenomena have not occurred is that of Puerto López because it is an area protected by the Machalilla National Park, there is no indiscriminate deforestation that threatens the local ecosystem. Also, the Plan for Development and Territorial Planning of Jipijapa (PD \& OT, 2015).

According to the threat map for mass movements, Jipijapa is among the cantons of the relatively high risk of landslide, reaching more than $30 \%$ of the exposed surface (PD \& OT, 2015). In order to zonify the areas susceptible to landslides, the criteria that reflect attributes that could provide information related to the field study were used. The zones identified in the study were three: high, medium and low.

The classification of the methods used to evaluate the susceptibility to breakage of a slope, as well as for the realization of maps, vary according to the authors (Corominas, 1987 and 1992, Carrara et al., 1995). The classification and description of the procedures presented here are based on an adaptation of the previous ones.

There are four main procedures used in the evaluation and preparation of susceptibility maps of the terrain to produce breaks in the slopes (hereinafter, susceptibility maps): deterministic, heuristic, probabilistic and geomorphological methods. According to Sarkary, K. (2004), susceptibility is categorized according to different criteria, which are described below.

Table 1

Criteria for classifying the degree of susceptibility to landslides

\begin{tabular}{ll}
\hline $\begin{array}{l}\text { Degree of } \\
\text { Susceptibility }\end{array}$ & Criteria \\
\hline Very high & $\begin{array}{l}\text { Slopes with fault zones, highly weathered and saturated soil masses } \\
\text { and unfavorable discontinuities where landslides have occurred or } \\
\text { there is a high possibility that they will occur. }\end{array}$ \\
High & $\begin{array}{l}\text { Slopes that have fault zones, high to moderate weathering and } \\
\text { unfavorable discontinuities where landslides have occurred or are } \\
\text { likely to occur. }\end{array}$ \\
& $\begin{array}{l}\text { Slopes with some fault zones, intense erosion or partially saturated } \\
\text { materials, where no landslides have occurred, but there is no complete } \\
\text { assurance that they do not occur. }\end{array}$
\end{tabular}


Low

Very low
Slopes that have some fissures, partially eroded, unsaturated materials, with favorable discontinuities, where there is no evidence to predict landslides.
Slopes
Non- weathered
with favorable discontinuities that do not present any symptoms of landslides.

As part of the investigation, the GPS points were located to identify the total area of study; for this, the area was visited and with the help of experts and experts in the area, the data of the boundaries were taken to form the polygon of Campus Los Angeles of UNESUM. Once the points were identified, they were entered as placemarks in the Google Earth Pro command to corroborate their veracity.

The area under study, is formed by accumulations and sedimentary deposits; all its cover is on the ONZOLE formation consisting of sandy clay, clay, and light brown siltstone, with intercalations of medium sandstone, somewhat calcareous, soft, yellowish brown; sandy clays with intercalations of medium sandstone, somewhat calcareous, sandy clays with intercalation of medium calcareous sandstone, sandy clays and light brown siltstones and clays and siltstones with silty sand spheroid concretions, brown to greenish gray (PDyOT, 2017)

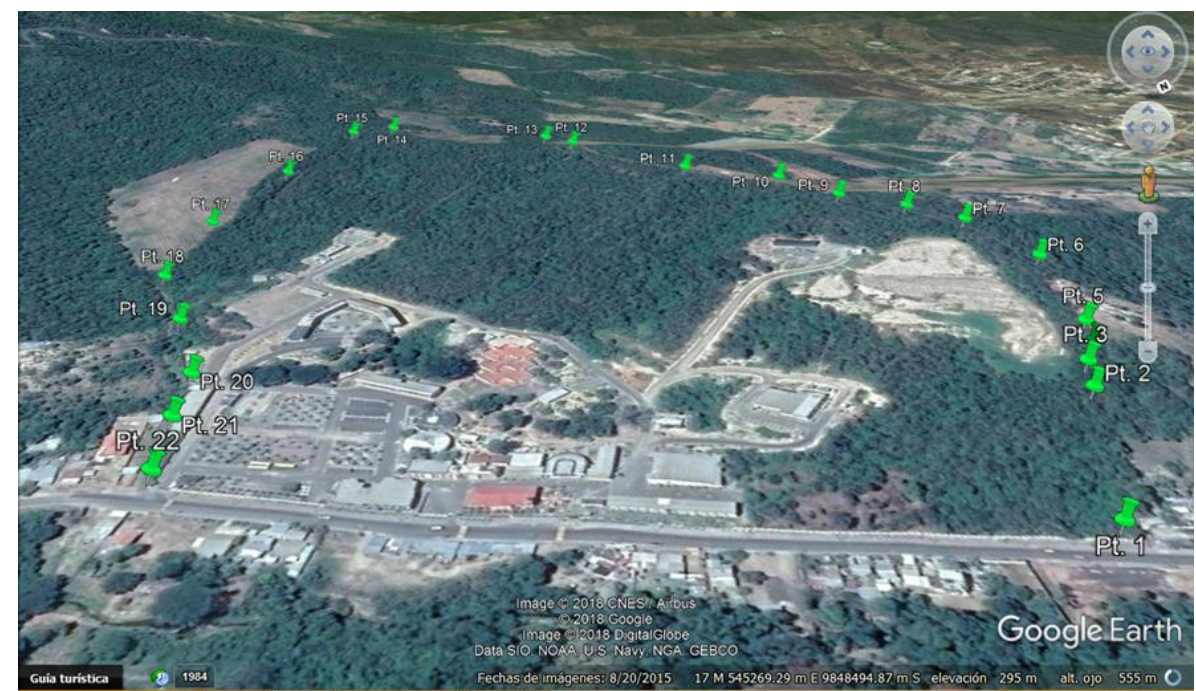

Figure 1. Registration of UTM points in Google Earth Pro (2017).

Successive points to UTM scales of the boundaries of Campus Los Angeles (2017)

In the area indicated the predominant relief is the hillside, made up of more than $80 \%$, with different levels of height (ato, medium and low), as well as its grades of slopes, in which the lowest reach up to $0^{\circ}$ and the steepest reach $70^{\circ}$. Its origin is erosive tectonic, with small terraces To a lesser extent are the steep, flat and almost flat reliefs. In the South-East direction is the Jipijapa River, which decreases considerably during the summer season. Jipijapa is located within the sub-accounts of the north coastal profile, surface water resources are scarce, available between January and April, so this area remains dry during the rest of the year.

The most significant basin is the Seco River of Jipijapa, that ends in the cove of Cayo towards the coast of the Pacific Ocean. This channel remains dry much of the year with contributions that appear in the winter season (INAMHI, 2018). In relation to this, in the territory that includes the Campus Los Angeles, there are channels of water drainages that have been formed by the erosive action of the rains; one of them descends from the hill, surrounding the extreme south, descending between the buildings of the Faculty of Economic Sciences and the Clinical Laboratories of the UNESUM and the other, by the extreme East of the facilities used by the nursing career.

Escobar, A. A. H., Santos, L. G. S., Viteri, C. G. V., Gamez, M. R., \& Gutiérrez, Y. de las M. A. (2019). Susceptibility to landslides in Los Angeles campus: Southern State University of Manabi. International Journal of Life Sciences, 3(1), 1-11. https://doi.org/10.29332/ijls.v3n1.240 
The soils of the Campus Los Angeles of the UNESUM are of the inceptisol type, which means that being of sedimentary formation they are just beginning to form (Iváñez et al., 2010). They are characterized by having a high content of clay and silt, hence there are impermeable areas in the area. Soils of clayey type and loamy clay occupy $90 \%$ of the territory and are scattered in the area in the form of patches or narrow strips.

In the soils of Campus Los Angeles, the native forest area of the area still predominates; there are also small areas of agricultural use that are used for reforestation and gardening projects. On the other hand, a large part of the territory has also been used for the construction of civil works both in the flat areas of the region, and in the upper part; there is a predominant type of vegetation such as dry scrub, and a small part is made up of a wooded area (Alfredo, 2011). Much of the vegetation native to the area has been deforested; instead, timber trees, fruit trees, and ornamental plants have been incorporated, in order to minimize the environmental impact that has been generated by the deforestation of the forests.

The high degree of anthropic intervention has led to the alteration of vegetation, which means that the earth's surface is exposed to more severe erosive processes and, therefore, geomorphological events such as landslides occur more frequently (Alfredo, 2011). The predominant climate in the region is classified as subwet, with a water deficit in the dry season (INAMHI, 2018). The average annual temperature is $250 \mathrm{C}$, registering the highest values in the month of March with $2800 \mathrm{C}$ and the minimum values with $22 \mathrm{C}$ in the month of July, the relative humidity varies between 70 and $90 \%$ depending on the time of the year. Rainfall has an annual average of about 500 and $750 \mathrm{~mm}$ per year, the months with the highest accumulated comprise the period between December and April and the months with the minimum values correspond to the months of March to November (INAMHI, 2018).

The predominant direction of the wind is from North to South, with monthly average speed that fluctuates between $1.4 \mathrm{~m} / \mathrm{s}$ and $1.7 \mathrm{~m} / \mathrm{s}$, being the average value of $1.6 \mathrm{~m} / \mathrm{s}$, although bursts of up to 12 are produced $\mathrm{m} / \mathrm{s}$ (Vanessa, 2011).

\section{Materials and Methods}

The first place visited was occupied by the facilities of the Nursing career, at the Los Angeles Campus of UNESUM, where several susceptibility factors could be identified. There were gullies formed by water erosion and subsidence of soils, slope cuts, eroded soils, deforested areas and collapse of drainage systems were also observed.

In this area there were 4 points where the presence of conditioning factors of susceptibility to landslides was visualized, located as indicated below).

Table 2

Location of the points susceptible to landslides in the area occupied by the facilities of The Nursing Career

\begin{tabular}{lllll}
\hline Points & East coordinated & North coordinate & Area & msnm \\
\hline 1 & $548328.00 \mathrm{~m} \mathrm{E}$ & $9850846.00 \mathrm{~m} \mathrm{~S}$ & $17 \mathrm{M}$ & 326 \\
2 & $548280.00 \mathrm{~m} \mathrm{E}$ & $9850814.00 \mathrm{~m} \mathrm{~S}$ & $17 \mathrm{M}$ & 337 \\
3 & $548345.00 \mathrm{~m} \mathrm{E}$ & $9850815.00 \mathrm{~m} \mathrm{~S}$ & $17 \mathrm{M}$ & 327 \\
4 & $548384.00 \mathrm{~m} \mathrm{E}$ & $9850789.00 \mathrm{~m} \mathrm{~S}$ & $17 \mathrm{M}$ & 326 \\
\hline
\end{tabular}

The data collection was done at points of evidence of affectations due to susceptibility factors to landslides in the Faculty of Economic Sciences of the UNEUM. Although in this zone there are constructions in flat places, a large part of the territory has an uneven topography. $20 \%$ of the main streets have a thin layer of ballast, evidencing cracks due to the removal of material due to the rains, leading to the possibility of a mass movement over time due to the instability of the cuts of the slopes and the hillside. On the other hand, direct damage to the construction was also evidenced, in that place the collapse of one of the walls that surround the parking lot was documented, the collapse of soil due to the potential action of water in clay soils was the main cause of this problem. 
Table 3

Location of the points susceptible to land slides in the area occupied by the facilities of the Faculty of Economics

\begin{tabular}{lllll}
\hline Points & Easting & Northing & Zone & $\mathrm{m}$ \\
\hline 1 & $548130.00 \mathrm{~m} \mathrm{E}$ & $9850775.00 \mathrm{~m} \mathrm{~S}$ & $17 \mathrm{M}$ & 364 \\
2 & $548180.00 \mathrm{~m} \mathrm{E}$ & $9850739.00 \mathrm{~m} \mathrm{~S}$ & $17 \mathrm{M}$ & 360 \\
3 & $548125.00 \mathrm{~m} \mathrm{E}$ & $9850707.00 \mathrm{~m} \mathrm{~S}$ & $17 \mathrm{M}$ & 373 \\
4 & $548224.00 \mathrm{~m} \mathrm{E}$ & $9850723.00 \mathrm{~m} \mathrm{~S}$ & $17 \mathrm{M}$ & 354 \\
\hline
\end{tabular}

There is also a stream which, in rainy seasons, collects water from the upper part, carrying organic, rocky and mud material. The channel that allows the evacuation of the water channel is in poor condition and is not given the necessary maintenance which could lead to an overflow and flood the lower parts of the sector. In this area, 4 parts were identified.

Table 4

Location of the points susceptible to landslides in the area occupied by the evacuation channel

\begin{tabular}{lllll}
\hline Points & Coordinated East & North Coordination & Area & msnm \\
\hline 1 & $548443.00 \mathrm{~m} \mathrm{E}$ & $9850617.00 \mathrm{~m} \mathrm{~S}$ & $17 \mathrm{M}$ & 337 \\
2 & $548485.00 \mathrm{~m} \mathrm{E}$ & $9850564.00 \mathrm{~m} \mathrm{~S}$ & $17 \mathrm{M}$ & 340 \\
3 & $548547.00 \mathrm{~m} \mathrm{E}$ & $9850509.00 \mathrm{~m} \mathrm{~S}$ & $17 \mathrm{M}$ & 340 \\
4 & $548528.00 \mathrm{~m} \mathrm{E}$ & $9850664.00 \mathrm{~m} \mathrm{~S}$ & $17 \mathrm{M}$ & 328 \\
\hline
\end{tabular}

\section{Results and Discussions}

The observation made in the areas selected for the development of the investigation made it possible to verify the presence of carcanens in the cuttings of slopes, landslides in the roads, soil erosion, landslides, and colluvial deposits, eroded slopes and the collapse of structures.

This type of problem occurs in clayey soils, when they become saturated with water they expand, pushing the structures and cracking them and, when their water level has decreased, they return to their normal state leaving the traces of their presence. The geomorphology of the sector corresponds to steep colonies with claysilt material, with a high degree of collapsibility and dispersion, which is why they are easily eroded by the effects of water allowing their passage too low areas or accumulation zones.

Table 5

The behavior of rainfall and average monthly temperature in the studied area (ANDIL 2016 weather data)

\begin{tabular}{lll}
\hline Months & $\begin{array}{l}\text { Temperature Average } \\
\left({ }^{\circ} \mathrm{C}\right)\end{array}$ & $\begin{array}{l}\text { Precipitation } \\
(\mathrm{Mm})\end{array}$ \\
\hline January & 25.8 & 132.8 \\
February & 26.0 & 312.8 \\
March & 27.0 & 316.4 \\
April & 26.6 & 221.6 \\
May & 26.3 & 72.0 \\
June & 25.9 & 8.8 \\
July & 25.3 & 2.2 \\
August & 24.2 & 7.0 \\
September & 25.2 & 0.0 \\
October & 24,9 & 8.8 \\
November & 24.7 & 0
\end{tabular}

Escobar, A. A. H., Santos, L. G. S., Viteri, C. G. V., Gamez, M. R., \& Gutiérrez, Y. de las M. A. (2019). Susceptibility to landslides in Los Angeles campus: Southern State University of Manabi. International Journal of Life Sciences, 3(1), 1-11. https://doi.org/10.29332/ijls.v3n1.240 


\begin{tabular}{lll} 
December & 24.9 & 7.1 \\
TOTAL & 25.5 & 1089.5 \\
\hline
\end{tabular}

The data presented in Table 5, clearly reflect that the rainiest months correspond to the period from January to April. Once the areas with a high and medium degree of susceptibility to landslides were defined, the nearby points were homogenized, creating polygons that prioritized each site with its standard or degree of importance, remaining as follows in figure 2 , with red dots (high susceptibility).

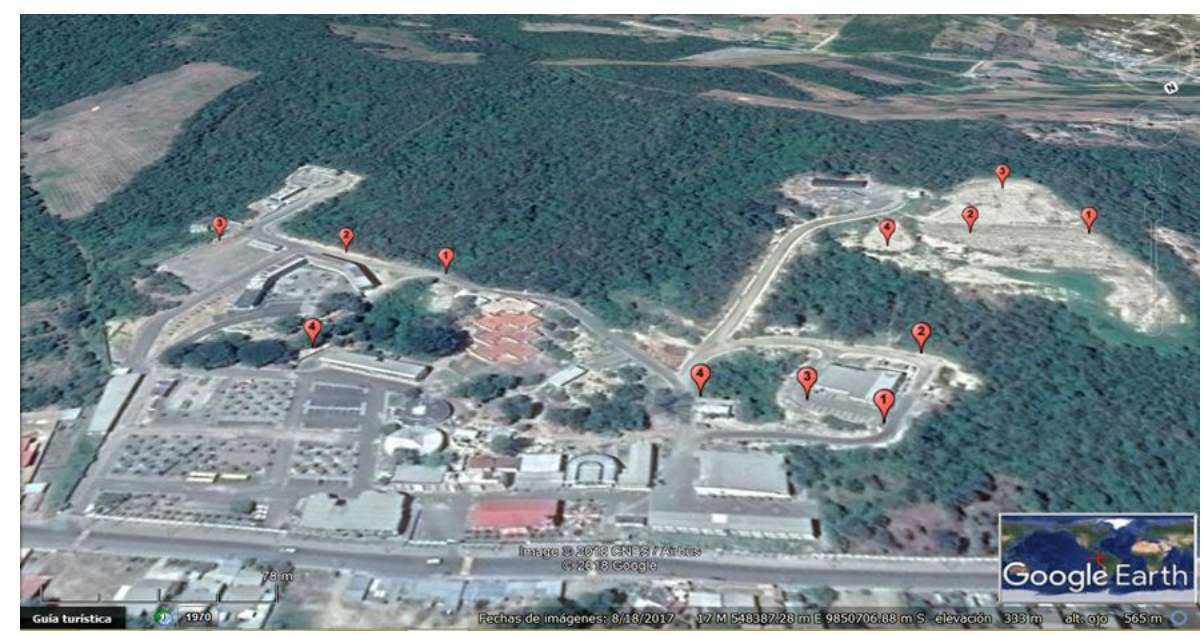

Figure 2. Indicios con alto grado de susceptibilidad a deslizamientos, puntos de color rojo (susceptibilidad alta)

Figure 3 shows the zones of a high degree of susceptibility to landslides, points of yellow color (medium susceptibility).

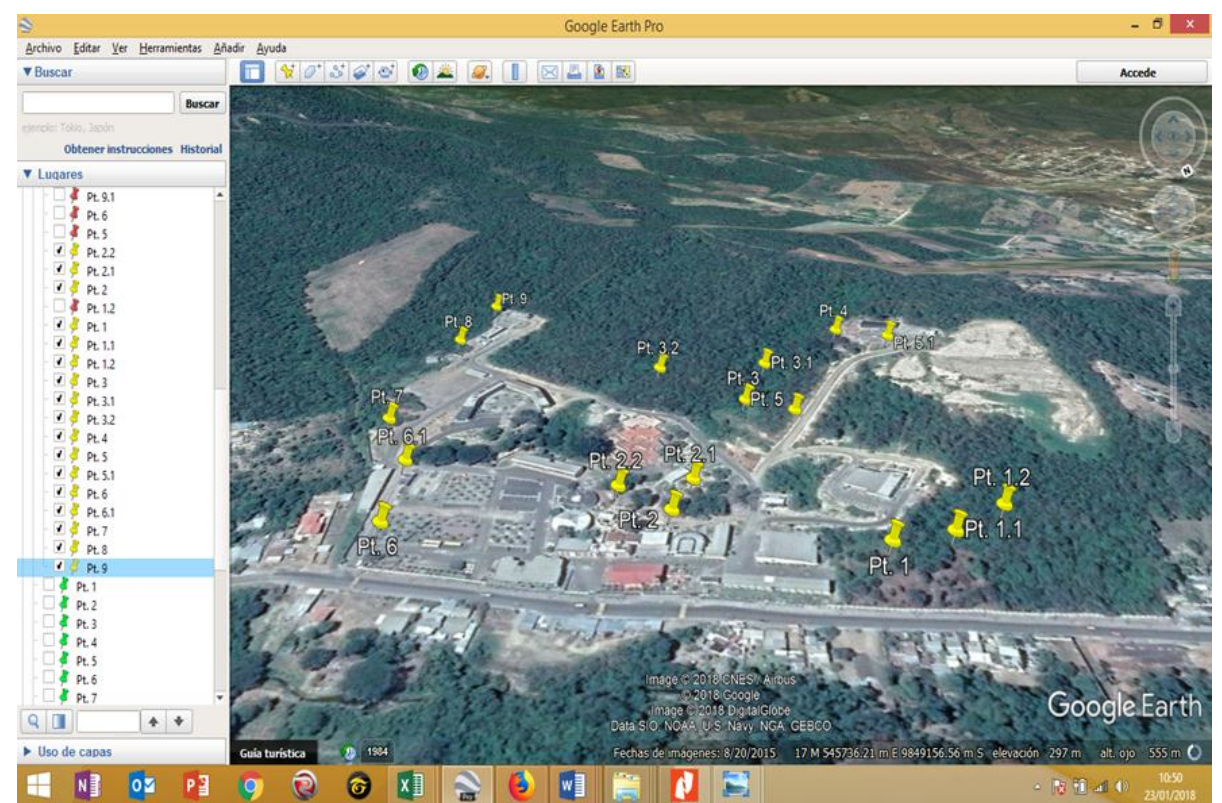

Figure 3. High degree of susceptibility to landslides, points of yellow color (medium susceptibility)

In correspondence with the work done, significant aspects were established to obtain the susceptibility map that, in turn, corroborate the solids of the referenced data. Next, the process in which the most important points that gave shape to polygons of high susceptibility were identified. 
In the previous sections, the methodology, materials, and techniques for the evaluation of the susceptibility to landslides have been described. Likewise, the results obtained in the environmental framework on geology, geomorphology, hydrography, climate, soil, and slope are shown, with respect to the study of the research field. In the first place, the landslides and their possible relation with the precipitating and conditioning factors have been studied. Next, the results obtained through the application of the procedure in the study area are detailed.

Three categories of susceptibility have been identified (high, medium and low). And in the map obtained, each one has been represented by its assessment of the factors that condition and trigger the landslides. ZONE 1 (Z1). Without color and green color: it is composed mainly of two regions; one located in the North part, in the limit of the zone of study, and another one to the South. It was determined that the susceptibility is low to very low and is due to the influence of topographic factors and the use of land (buildings, roads, and recreational spaces) that mitigate the process of weathering and erosion, that is, keep the soil surface protected. However, in the North of the region, the vegetation is moderate and does not allow susceptibility to having a greater degree.

Low (Z1). This region occupies 28\% (8.26 ha) of the study area; It is constituted by slopes that have some fissures, mainly saturated materials, not eroded, with favorable discontinuities where there are no signs to predict landslides. They are found on flat or almost flat slopes, with an inclination range between $5^{\circ}$ to $25^{\circ}$ and a prominent vegetation cover. Unidentified or null area. Occupies 51\% (14.75 ha) of the studied area, it also presents areas with flat and almost flat slopes, with a prominent vegetation cover; the few hillsides that were identified are not weathered and show favorable discontinuities without presenting any factor that presumes the occurrence of landslides. Figure 4. Representation of the polygons with a high average and low susceptibility to landslides of the Los Angeles Campus of the UNESUM (Points of high susceptibility georefined in the Map).

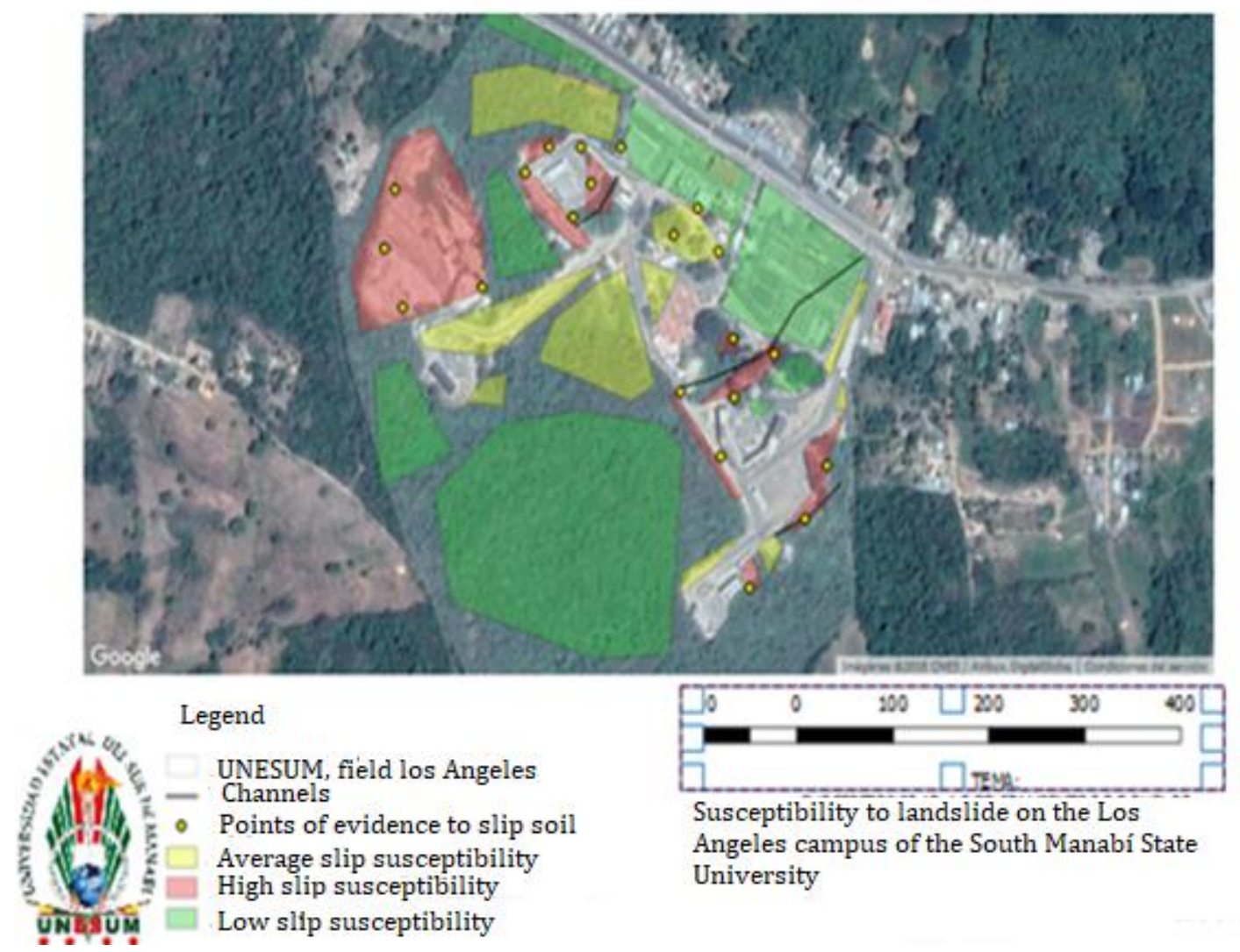

Figure 4. Susceptibility to a landslide on the Los Angeles campus

Escobar, A. A. H., Santos, L. G. S., Viteri, C. G. V., Gamez, M. R., \& Gutiérrez, Y. de las M. A. (2019). Susceptibility to landslides in Los Angeles campus: Southern State University of Manabi. International Journal of Life Sciences, 3(1), 1-11. https://doi.org/10.29332/ijls.v3n1.240 
ZONE 2 (Z2) -Represented in yellow; it is a medium-sized area distributed in low-altitude areas where the soil is made up of sandy clay, clay, and siltstone, poorly provided with vegetation, also has civil structures or a deforested area. This contributes to an increase in the susceptibility that, together with the weight assigned to the topographic factors, leads to a low susceptibility.

Medium (Z2) -In this region, eight (8) zones could be identified that are susceptible to landslides, which make up 7\% (2.11 ha) of the total area under study. A steep relief is present to a great extent, with a range of inclination that goes from $35^{\circ}$ and $50^{\circ}$ according to the representation. Hillsides were identified with some areas of fault, intense erosion or partially saturated, in this area no landslides were identified, but there are conditions for them to occur if triggering processes occur. This region is located in the central part of the study area, where there are mainly buildings and access roads, it is shown in figure 5.
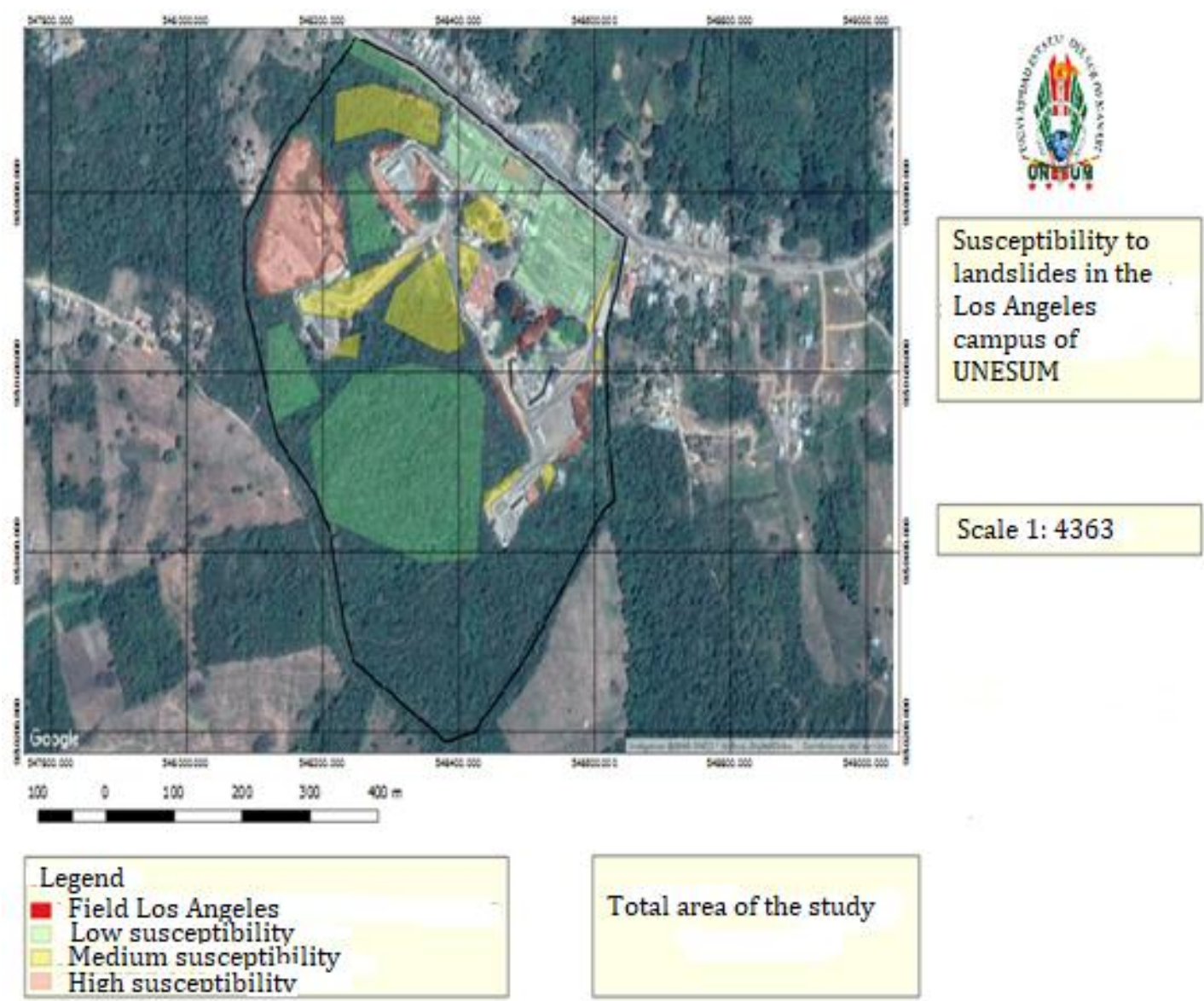

Scale 1: 4363

Figure 5. Map of high average and low susceptibility to landslides of Campus Los Angeles of UNESUM

ZONE 3 (Z3. Red color: The most influential signs in the variation of the susceptibility to landslides are moderated by the weights registered in the variables both conditioning as detonators, in this case they have been categorized and assigned as the most important to the slope, length of the break (in case of finding active landslides), vegetation cover, type of soil and existing affectations in the structures due to landslides. These signs were recorded in the most critical parts and are those that model the degree of susceptibility to landslides

High (Z3. Nine (9) zones highly susceptible to landslides were identified, which make up $13 \%$ (3.91 ha) of the total area studied, the main characteristics of the terrain are steep slopes with a range of inclination that moves between $50^{\circ}$ and $70^{\circ}$; Litter is inceptisol formation composed of clays and silt (brown, white, yellowish, sandy and silty clay) deforested and, to a large extent, eroded.

The presence of affected structures, which are prone to collapse, was corroborated and in their effect also several slightly pronounced gullies caused by the extrinsic erosive processes were observed. Although no 
active landslides were observed, the possibility that these occur in the future due, essentially, to the conditioning and triggering factors such as slope, slope instability, and erosion is not ruled out. The faculty of Economic Sciences seems to be the most affected since there were collapsed structures. It is worth mentioning that, in the case of triggering factors, new landslides could occur in the identified zones.

\section{Conclusion}

The research was able to identify three categories of zones susceptible to landslides, evaluating them as high, medium and low; they are represented by the qualitative results of each variable of the conditioning and triggering factors, which have been shaped into polygons: In the same way the fundamental data for the conception of the map were obtained in the field study where samples were taken and documented for be reflected in the zoning of the final soil susceptibility map on the Los Angeles campus of UNESUM.

It was possible to identify the conditioning and triggering factors by obtaining thematic maps (geological, geomorphological, hydrographic and slope) which provided georeferenced data using GIS. It was also possible to capture the bibliographic concepts referenced in the theoretical framework of the research, which corroborates that these model the equilibrium state of the terrain. The application of the observation method allowed to observe, measure and document the conditions of susceptibility to landslides in the field of study, in the same way, the GIS constituted a tool that allowed managing simultaneously multiple layers of georeferenced information in a fast and efficient way.

The final map of susceptibility to landslides for the Los Angeles campus was prepared with thematic maps as fundamental inputs; geological, geomorphological, hydrological, slope, which allowed to know the study area from the use of GIS, which were obtained in the field study where samples were taken to be captured in the zoning of the final soil susceptibility map on the Los Angeles campus of the UNESUM.

\section{Acknowledgments}

The authors acknowledge the support of the students who were linked to the research thanks to their effort the planned objectives were fulfilled.

Escobar, A. A. H., Santos, L. G. S., Viteri, C. G. V., Gamez, M. R., \& Gutiérrez, Y. de las M. A. (2019). Susceptibility to landslides in Los Angeles campus: Southern State University of Manabi. International Journal of Life Sciences, 


\section{References}

Alfredo, G. (2011). Study of the environmental impacts of the potable water distribution system of the city of Jipijapa: Manabí, Ecuador.

Brabb, E. E. (1989). Landslides: Extent and economic significance in the United States. In 28th International Geological Congress Symposium on Landslides (pp. 25-50).

Carrara, A., Cardinali, M., Detti, R., Guzzetti, F., Pasqui, V., \& Reichenbach, P. (1991). GIS techniques and statistical models in evaluating landslide hazard. Earth surface processes and landforms, 16(5), 427-445. https://doi.org/10.1002/esp.3290160505

Corominas, J., \& García Yagüe, A. (1997, November). Terminología de los movimientos de ladera. In IV Simposio nacional sobre taludes y laderas inestables. Granada (Vol. 3, pp. 1051-1072).

Corominas, J., \& Moya, J. (2008). A review of assessing landslide frequency for hazard zoning purposes. Engineering geology, 102(3-4), 193-213. https://doi.org/10.1016/j.enggeo.2008.03.018

INAMHI. (2018). Books, A. M. National Institute of Meteorology and Hydrology. Bulgarian Academy of Sciences, Sofia (in Bulgarian).

Ivañez, I., Santiuste, C., \& Sanchez-Saez, S. (2010). FEM analysis of dynamic flexural behaviour of composite sandwich beams with foam core.Composite Structures, 92(9), 2285-2291. https://doi.org/10.1016/j.compstruct.2009.07.018

Meza, A. K. T., Freyre, J. R. A., Cevallos, M. G. O., \& Pico, M. J. M. (2018). Autonomy, Good Humor and Support Networks, Potential of Community Resilience Intervention in People Victims of the Earthquake in the Calderón Parish. International Research Journal of Management, IT and Social Sciences, 5(1), 1-8.

PD and OT. (2015). Plan for the development and territorial organization of the Jipijapa canton of 2015 . p.121. Biophysical component.

PD and OT. (2017). Development and territorial ordering plan. the Jipijapa canton.

Sarkar, S., \& Kanungo, D. P. (2004). An integrated approach for landslide susceptibility mapping using remote sensing and GIS. Photogrammetric Engineering \& Remote Sensing, 70(5), 617-625. https://doi.org/10.14358/PERS.70.5.617

Suárez, J. D. (1998). Landslides and slope stability in tropical zones. Bucaramanga, Colômbia: Instituto de Investigaciones sobre Erosion y Deslizamientos.

Vanessa, M. (2011). System of indicators to evaluate the environmental impact of anthropogenic activity. The Carrizal-Chone watershed. 


\section{Biography of Authors}

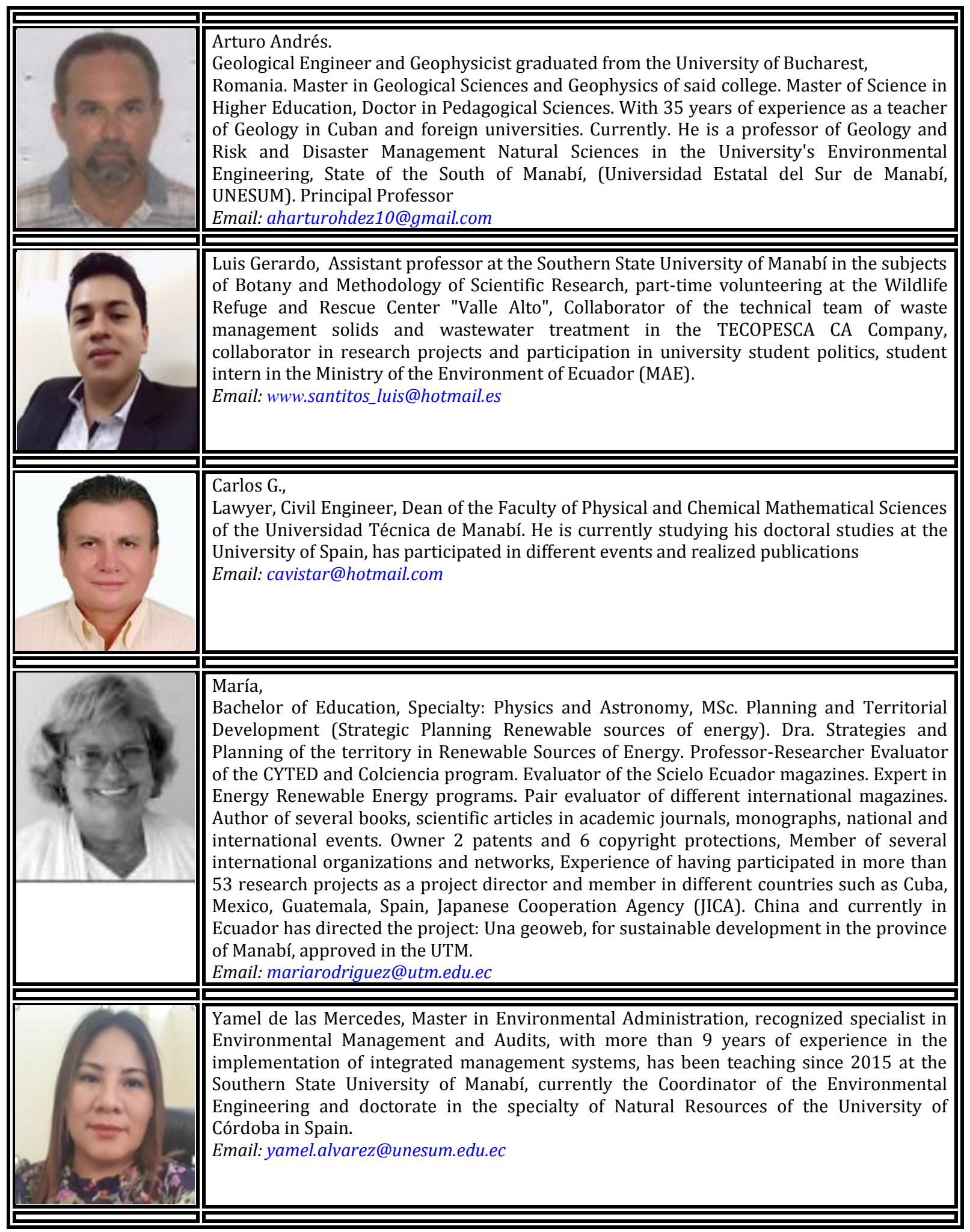

Escobar, A. A. H., Santos, L. G. S., Viteri, C. G. V., Gamez, M. R., \& Gutiérrez, Y. de las M. A. (2019). Susceptibility to landslides in Los Angeles campus: Southern State University of Manabi. International Journal of Life Sciences, 3(1), 1-11. https://doi.org/10.29332/ijls.v3n1.240 